\title{
Progress in EUV resists for contact holes printing using EUV interference lithography
}

\author{
Xiaolong Wang $^{\mathrm{a}^{*}}$, Li-Ting Tseng ${ }^{\mathrm{a}}$, Iacopo Mochi ${ }^{\mathrm{a}}$, Michaela Vockenhuber ${ }^{\mathrm{a}}$, Lidia van Lent-Protasova ${ }^{\mathrm{b}}$, Rolf \\ Custers $^{\mathrm{b}}$, Gijsbert Rispens ${ }^{\mathrm{b}}$, Rik Hoefnagels ${ }^{\mathrm{b}}$, Yasin Ekinci ${ }^{\mathrm{a}}$ \\ aPaul Scherrer Institute, CH-5232 Villigen PSI, Switzerland

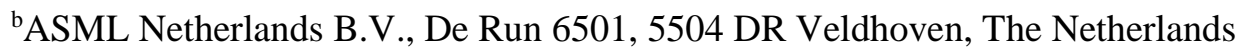

\begin{abstract}
Using high-resolution extreme ultraviolet interference lithography (EUV-IL), we investigated contact hole/pillars printing performance of several EUV resist platforms for the high-NA EUV lithography. We compared the dose and local critical dimension uniformity (LCDU) of the three chemically-amplified resists (CARs) with the best performance for printing contact holes (CHs) at half pitch (HP) of 24 and $20 \mathrm{~nm}$. One of the CARs showed the lowest LCDU, 2.3 and $2.2 \mathrm{~nm}$ with lowest dose 16.4 and $21.1 \mathrm{~mJ} / \mathrm{cm}^{2}$ for HP 24 and $20 \mathrm{~nm}$, respectively. With the inorganic resist we obtained $38.8 \mathrm{~mJ} / \mathrm{cm}^{2}$ with an LCDU of $1.3 \mathrm{~nm}$ for HP $20 \mathrm{~nm}$ pillars. We have also studied the effects of the resist thickness and post-exposure baking (PEB) temperature on the dose and LCDU. These results show that there are promising CAR and non-CAR resists for $\mathrm{CH}$ printing towards high-NA EUVL.
\end{abstract}

Keywords: Extreme ultraviolet lithography, EUVL, interference lithography, contact holes, High-NA, Resist CAR/inorganic, dose-to-size, LCDU

\section{INTRODUCTION}

In the last two decades EUV lithography (EUVL) has been developed to enable future progress in semiconductor manufacturing [1, 2], and this year it has entered into the high-volume manufacturing (HVM) phase at $7 \mathrm{~nm}$ technology node $[3,4]$. To enable future progress, high-NA EUVL is considered as the most viable option. To make sure that the HVM high-NA EUVL can be introduced to the market on time, EUV resists have to be developed that can resolve at $5 \mathrm{~nm}$ node and beyond with high sensitivity and how the line edge roughness (LER). Therefore, further research and development are needed to find the best EUV resists with optimal resolution-LER-sensitivity (RLS) [5]. To achieve this goal, it is necessary to develop, evaluate and understand the underlying mechanism of EUV resists before high-NA tools become available.

The EUV-IL end station at the XIL-II beamline of the Swiss Light Source (SLS) is a powerful and cost-effective tool to evaluate resist performance [2, 6-13]. One good advantage of the EUV-IL is that we use the coherent light from synchrotron with the wavelength $\lambda=13.5 \mathrm{~nm}$, so the theoretical resolution limit of this technique is HP $3.5 \mathrm{~nm}$ [14], that is much higher than the current and future EUV scanner with 0.33NA and NA (0.55NA) [3]. The XIL-IL endstation has successfully achieved world record of $6 \mathrm{~nm}$ HP [15] and demonstrated single digital resolution down to $2.5 \mathrm{~nm}$ technological node [14]. With the XIL-IL endstation we can investigate the LER/LWR, LCDU, and sensitivity of the EUV resist platforms at high resolutions and thereby contribute to the global efforts of EUV resist development.

In this work, we present the recent overview of the state-of-art EUV resists for printing contacts (holes and pillars). After evaluation of $\sim 20$ resists with different processing parameters, such as post-expose bake (PEB), post-apply bake (PAB), development time/materials, and resist thickness, we singled out three best performance resists for HP $24 \mathrm{~nm}$ and HP 20 $\mathrm{nm}$ for CHs. We assessed the readiness of the EUV resist for HVM high-NA EUVL by comparing the critical parameters,

35th European Mask and Lithography Conference (EMLC 2019), edited by Uwe F.W. Behringer,

Jo Finders, Proc. of SPIE Vol. 11177, 111770U - (c) 2019 SPIE

CCC code: $0277-786 X / 19 / \$ 21 \cdot$ doi: $10.1117 / 12.2535678$ 
including local critical dimension uniformity (LCDU) and dose, of the three resists categorized as two platforms (inorganic resist and CAR resist). For pillars printing, we demonstrated that PEB can substantially influence the dose and LCDU on inorganic resists.

\section{EXPERIMENTAL METHODS}

The resist evaluation is performed by the interference lithography XIL-IL tool. Its working principle is schematically shown in Fig. 1. The transmission mask is illuminated perpendicularly with the plane wave (EUV light from the synchrotron SLS) polarized along the horizontal direction and the gratings. The diffracted beams from a grating pair interfere (with a relative angle of $\theta$ ) on the surface of the photoresist-coated silicon wafer. We use the first-order diffracted beams for interference, and the relationship between the diffraction angle and the grating pitch is calculated as:

$$
\sin (\theta / 2)=\lambda / P
$$

where $\theta / 2$ is the diffraction angle and is the period of the grating $(P)$. The period of the interfered sinusoidal aerial image is given as

$$
p=\lambda / 2 \sin (\theta / 2)=P / 2
$$

As seen, the aerial image has a period $(p)$ which is half of the grating period, which is one of the advantages of the interference lithography. With the wavelength $\lambda=13.5 \mathrm{~nm}$, the theoretical resolution limit of this EUV-IL is $3.5 \mathrm{~nm}$ [14].

The gap between the mask and the wafer surface varies depending on the pitch of the grating and is determined with the following equation:

$$
g=\frac{d}{2 \tan (\theta / 2)}
$$

where $g$ is the gap between the grating and the interference pattern (mask-wafer distance) and $d$ is the distance between the two gratings. We note that the depth-of-focus of the aerial image is infinite, which means that with the changing gap, the contrast of the image does not change. The Eq. 3 is the optimal distance of mask-to-gap, for the maximum area of the aerial image.

The formation of the aerial image can be line/space pattern, contact holes (CHs) or pillars pattern or pattern with triangle lattice $[14,16]$. Figures 1(b) and (c) show two different grating configurations, two-beam and four-beam, which produce line/space and CHs or pillars. The details of effective double exposure theory for creating the CHs or pillar with EUV-IL is described elsewhere [16]. 


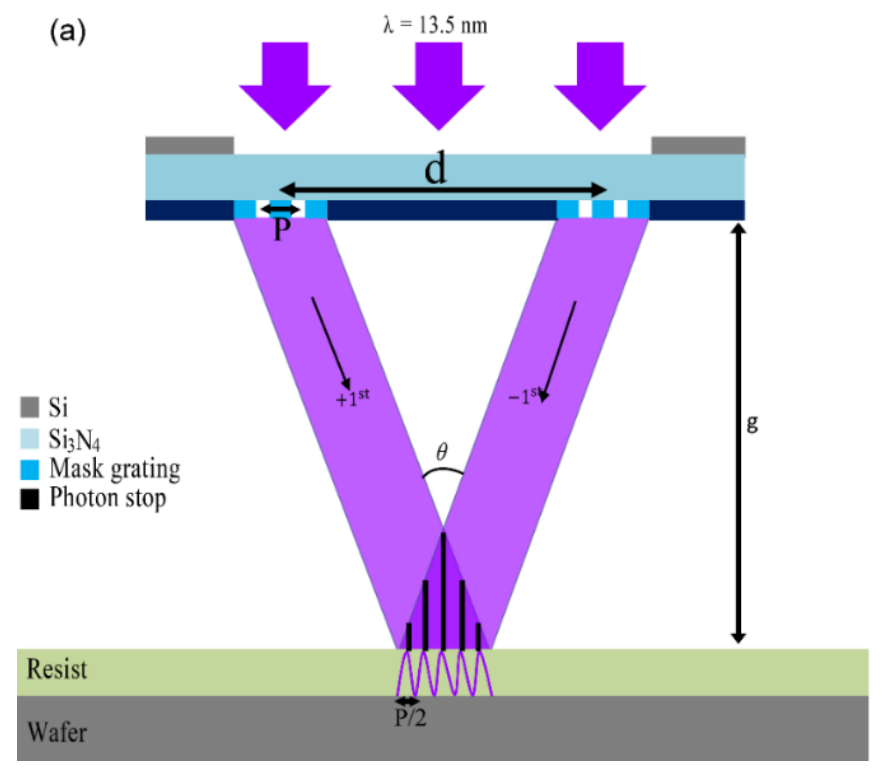

(b)

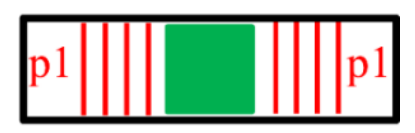

(c)

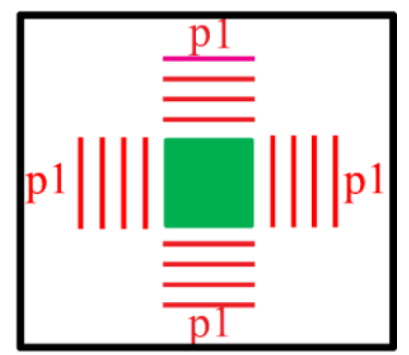

Figure 1. (a) EUV interference lithography scheme. EUV light illuminates a transmission mask from the top. The mask consists of transmission diffraction gratings. The diffracted coherent beams from an interference pattern which is recorded in the photoresist. (b) Two-beam interference grating layout. (c) Grating arrangement for the case of coherent four-beam interference.

\section{RESULTS}

In this section, we present the performance of the resists, including CAR and inorganic resists, from five vendors, which we have tested by printing CHs. First, we show the three resists with the best performance out of $\sim 20$ resists for HP 24 and $20 \mathrm{~nm}$ for CHs printing. Also, we compare the critical parameters of the selected resists with promising performance. To characterize the resist, the exposed patterns were analyzed with SEM (Carl Zeiss SUPRA 55VP) at the acceleration voltage of $1 \mathrm{kV}$ and $7.5 \mu \mathrm{m}$ aperture. The CD values were calculated with in-house developed software, and the LCDU values are estimated using $3 \sigma$ [17].

The SEM images of the resists with the best performance for HP 24 and $20 \mathrm{~nm}$ are shown in Fig. 2. The dose dependences of CD and LCDU for these resists are plotted in Fig. 3. The full comparison of the dose and LCDU for all three resists is listed in Table 1. All three resists have resolved both HP 24 and $20 \mathrm{~nm}$. CAR resist C resolved both pitches with the lowest doses of 16.4 and $21.1 \mathrm{~mJ} / \mathrm{cm}^{2}$, respectively. Also, resist C shows lowest LCDU of 2.3 and $2.2 \mathrm{~nm}$. The CAR resist C seems to be the most promising candidate for $\mathrm{CH}$ printing as it gives low LCDU at low dose. 
CAR A

(a)

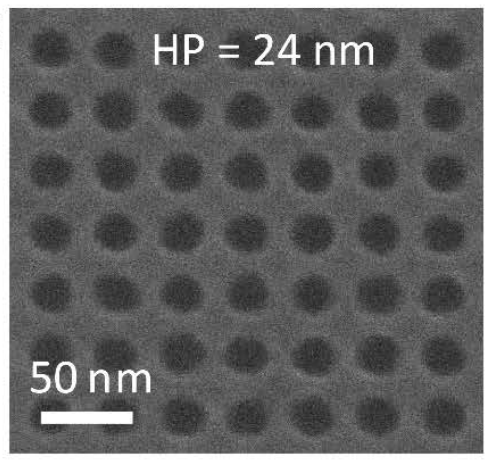

(d)

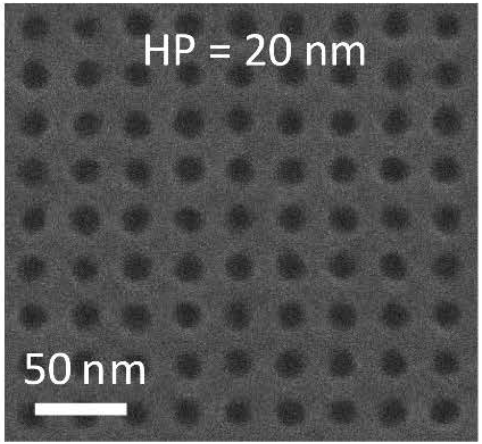

CAR B

(b)

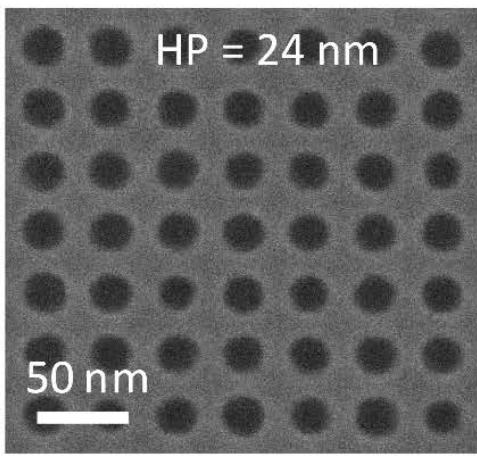

(e)

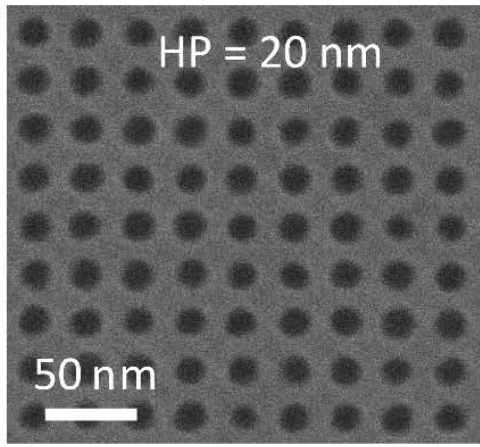

CAR C

(c)

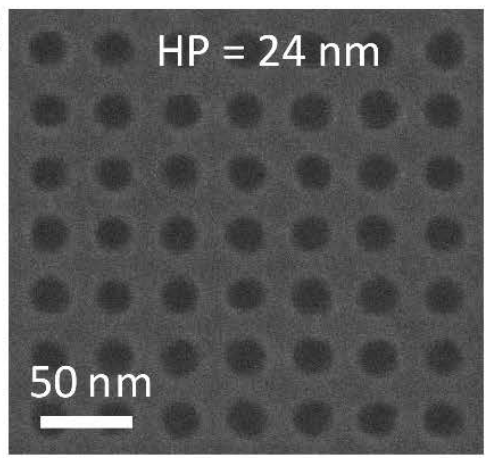

(f)

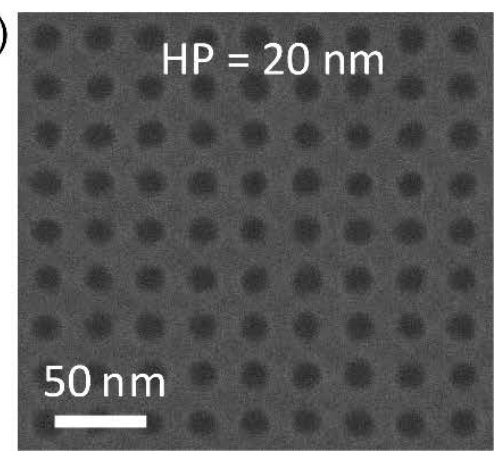

Figure 2. SEM images of CH patterns with different CARs. (a) CAR A, (b) CAR B and (c) CAR C for HP $24 \mathrm{~nm}$; (d) CAR A, (e) CAR B and (f) CAR C for HP $20 \mathrm{~nm}$.
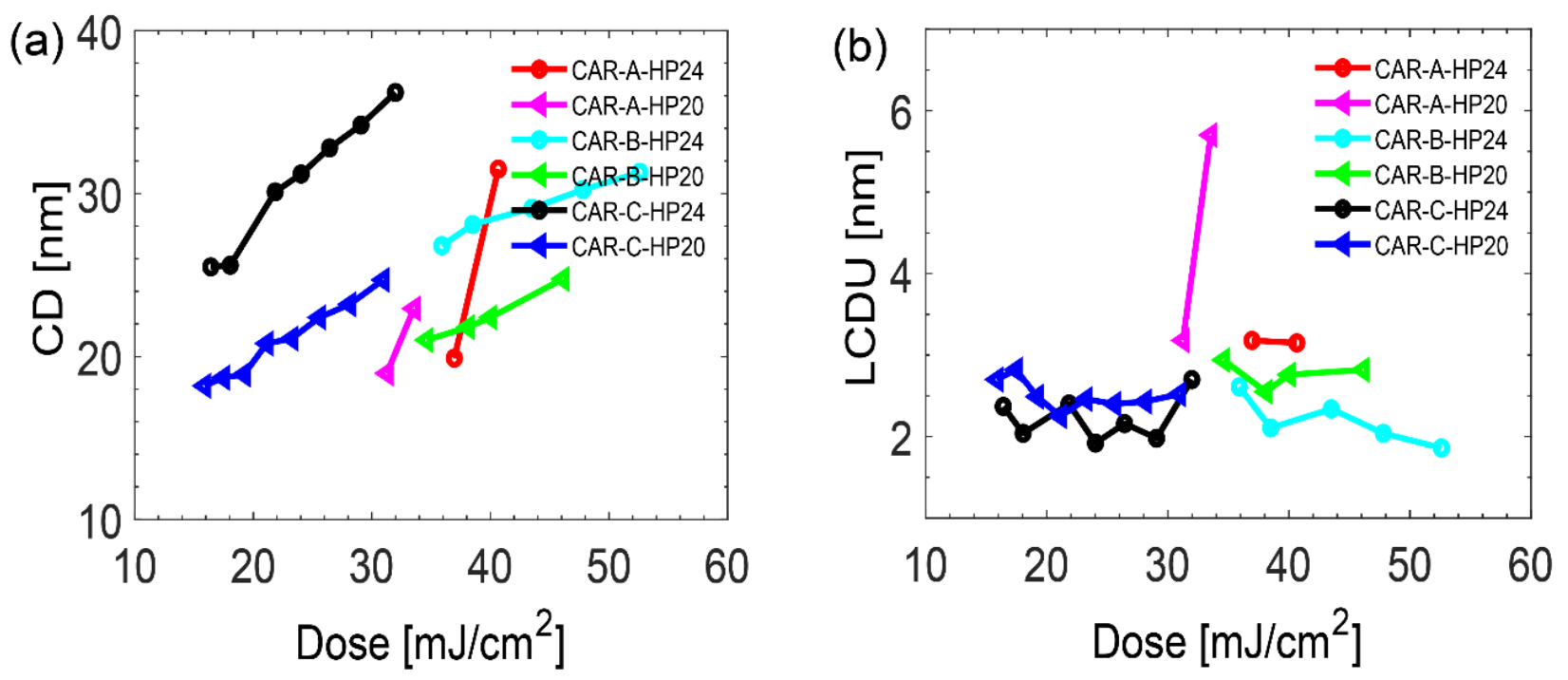

Figure 3. Resists with the best performance: (a) CD vs dose, (b) LCDU vs dose. 
Table 1. CD, Dose, and LCDU of the resists with the best performance for HP 24 and $20 \mathrm{~nm}$.

\begin{tabular}{|c|c|c|c|c|}
\hline HP (nm) & Vendor & CAR resist & Dose $\mathbf{( m J / \mathbf { c m } ^ { 2 } )}$ & LCDU (nm) \\
\hline \multirow{3}{*}{24} & Vendor 1 & A & 36.9 & 3.2 \\
\cline { 2 - 5 } & Vendor 2 & B & 35.9 & 2.6 \\
\cline { 2 - 5 } & Vendor 3 & C & 16.4 & 2.3 \\
\hline \multirow{3}{*}{20} & Vendor 1 & A & 31.2 & 5.7 \\
\cline { 2 - 5 } & Vendor 2 & B & 34.6 & 2.9 \\
\cline { 2 - 5 } & Vendor 3 & C & 21.1 & 2.2 \\
\hline
\end{tabular}

The effects of resist thickness and PEB on the dose and LCDU were studied using the inorganic resist. Fig. 4 shows the SEM images of the HP $20 \mathrm{~nm}$ pillars exposed using inorganic resist A with two different thickness. The dose dependences of CD and LCDU for the different thicknesses are plotted in Fig. 5. One can see that there is not too much change for both CD and LCDU for the two different resist film thicknesses. The quantitative comparison of dose to size and LCDU is listed in Table 2. The thickness (in this range) hasn't shown pronounced effect on the dose.

The effect of PEB temperature on inorganic resist B was also studied. Fig. 6 shows the SEM images of HP 20 nm pillar patterns obtained with two different PEB temperatures. The PEB2 was $10{ }^{\circ} \mathrm{C}$ higher than PEB1 (Fig. 7). The results confirm that the PEB T has a strong influence on the dose, influencing the thermal cross-linking that acts like an exposure. Thus, higher PEB will eventually decrease the dose. For the target CD, the required dose is $42 \%$ lower for PEB 2 than the one of PEB1, as shown in Table.3. The LCDU is only $0.3 \mathrm{~nm}$ higher in case of PEB2 (1.9nm) compared to the PEB1 (1.6 $\mathrm{nm})$. These results show that for the required dose and roughness PEB temperature can be optimized.

(a)

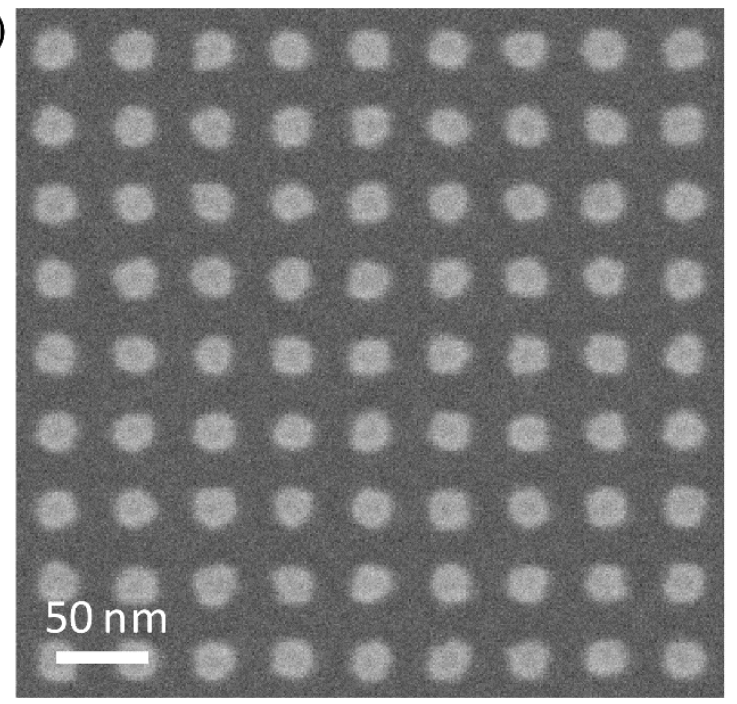

(b)

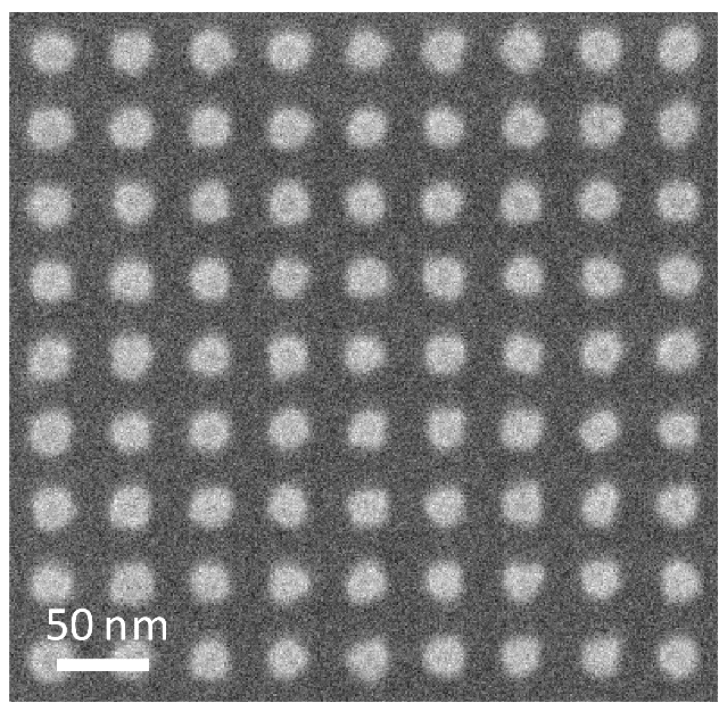

Figure 4. Plane-view SEM images:(a) inorganic A thickness 1, (b) inorganic A thickness 2. 

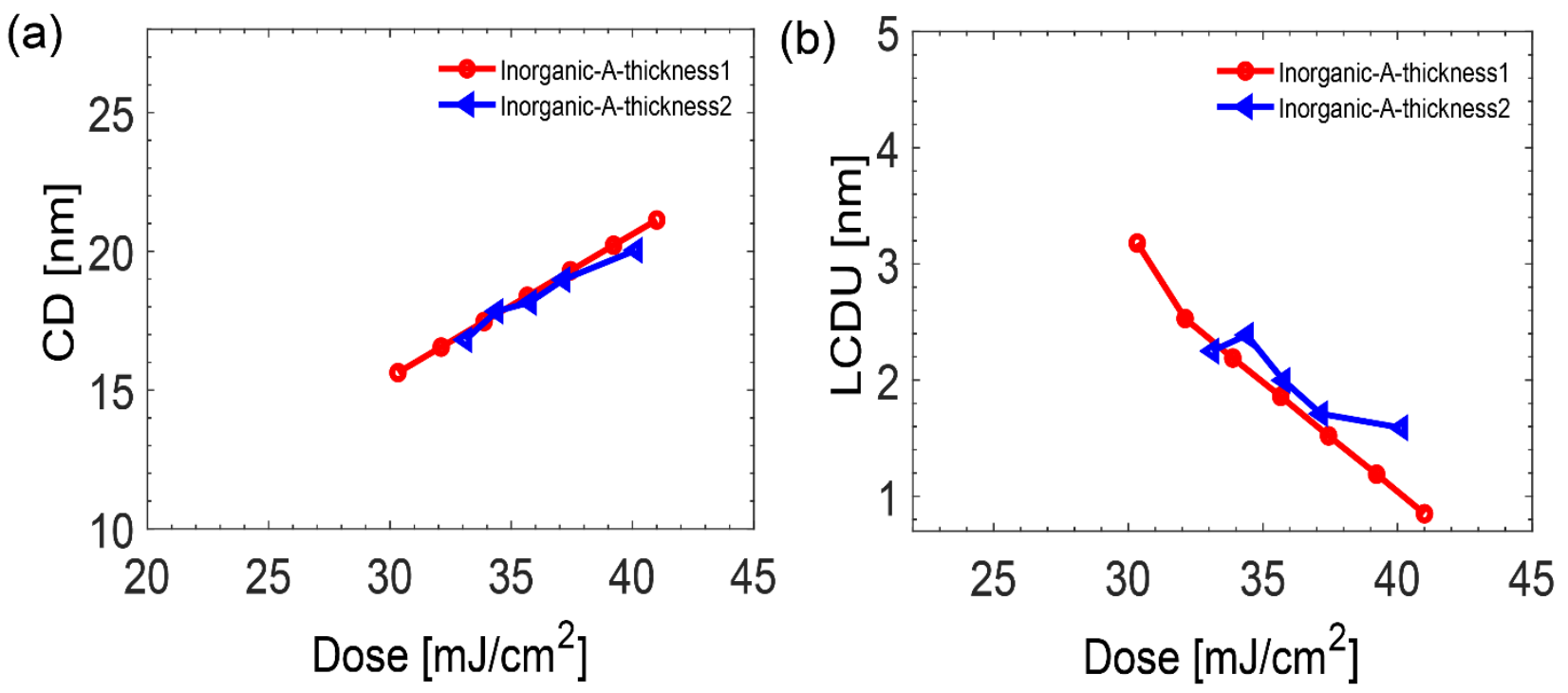

Figure 5. (a) CD vs dose for the different resist film thickness. (b) LCDU vs dose for the different resist film thickness

Table 2. Dose-to-size, and LCDU for the resists with different film thicknesses (HP $20 \mathrm{~nm}$ ).

\begin{tabular}{|c|c|c|c|c|}
\hline Vendor & Resist & Thickness & Dose $\mathbf{( m J / \mathbf { c m } ^ { 2 } )}$ & LCDU (nm) \\
\hline \multirow{2}{*}{ Vendor 1 } & Inorganic A & 1 & 38.8 & 1.3 \\
\cline { 2 - 5 } & Inorganic A & 2 & 40.1 & 1.6 \\
\hline
\end{tabular}

(a)

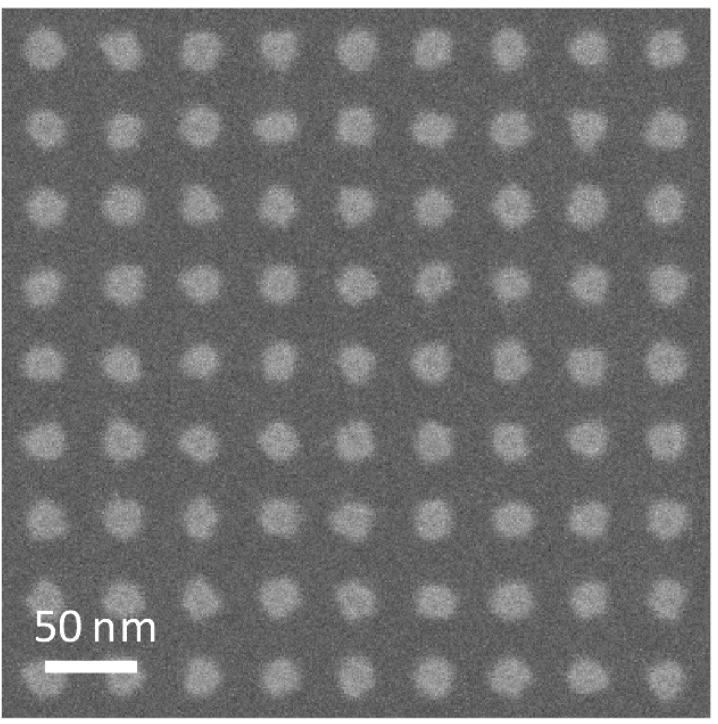

(b)

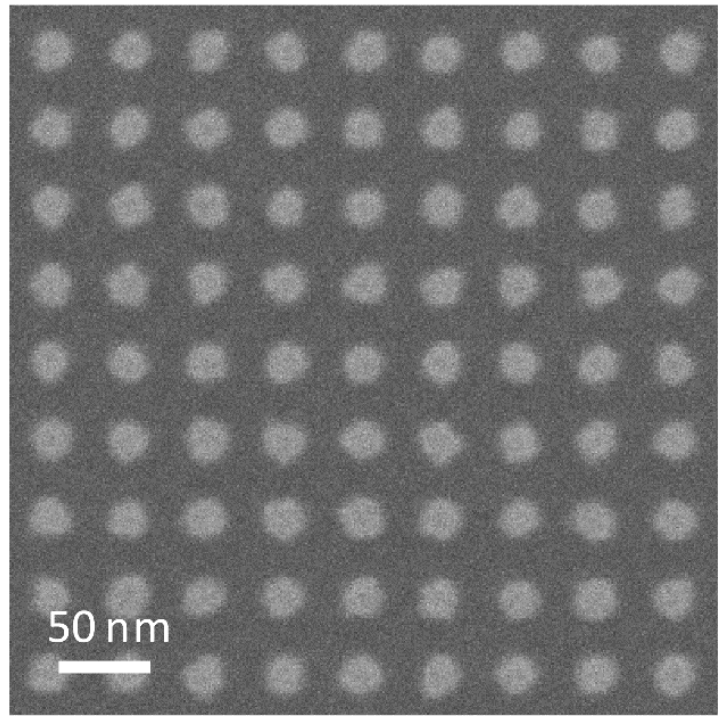

Figure 6. Plane-view SEM images of (a) inorganic resist at PEB1, (b) inorganic resist at PEB2. 

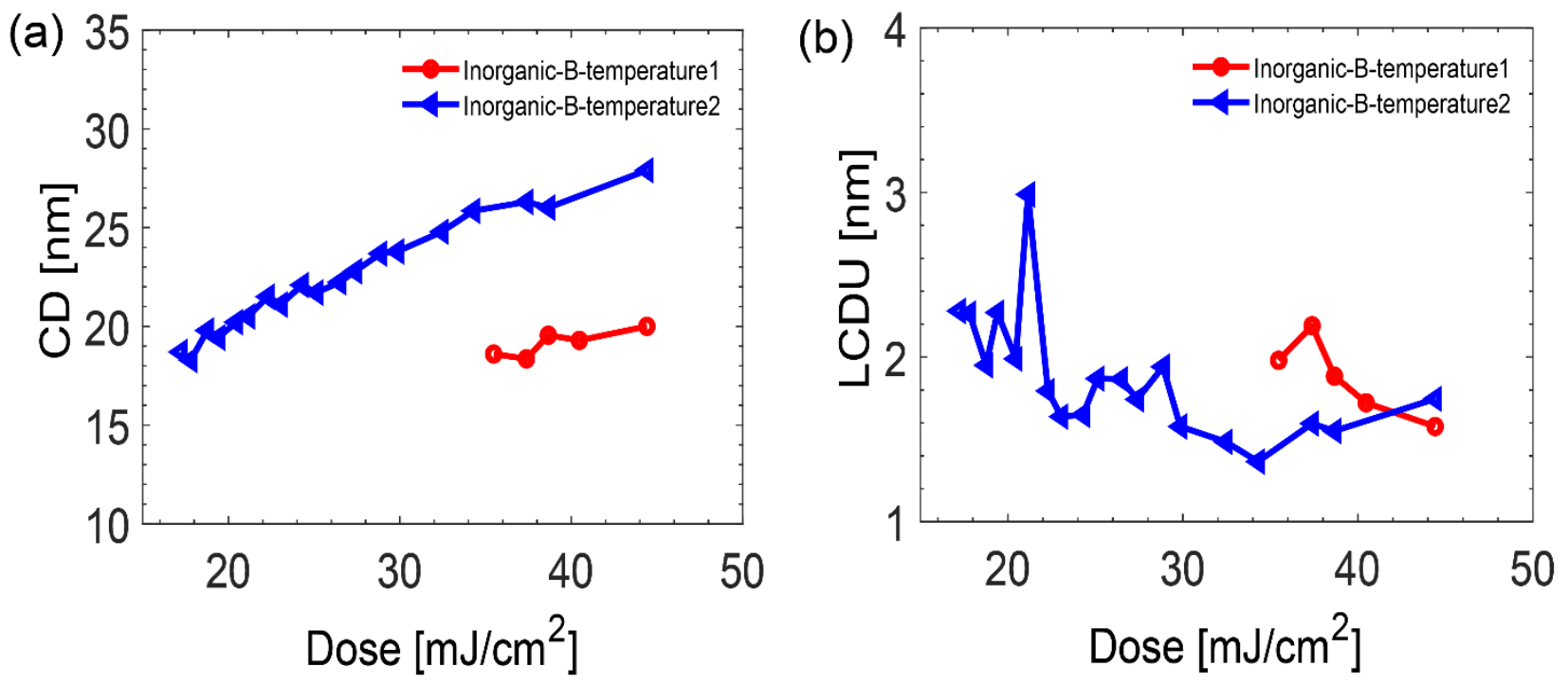

Figure 7. Performance of the inorganic resist at two different PEB temperatures: (a) CD vs dose; (b) LCDU vs dose.

Table 3. Dose-to-size, and LCDU of the inorganic resist for HP $20 \mathrm{~nm}$ at PEB1 and PEB2.

\begin{tabular}{|c|c|c|c|c|}
\hline Vendor & Resist & Temperature & Dose $\mathbf{( m J / \mathbf { c m } ^ { 2 } )}$ & LCDU (nm) \\
\hline \multirow{2}{*}{ Vendor 1 } & Inorganic B & 1 & 44.4 & 1.6 \\
\cline { 2 - 5 } & Inorganic B & 2 & 18.8 & 1.9 \\
\hline
\end{tabular}

\section{CONCLUSIONS}

We presented the results of the EUV resist screening for printing contact holes/pillars with the EUV-IL tool at the PSI XIL-II beamline. The three selected CAR resists with the best performance could resolve HP 24 and HP 20 nm CHs. The CAR resist $C$ requires the lowest dose to resolve both HP 24 and HP $20 \mathrm{~nm}$ with low LCDU. The inorganic resist shows that both resist thickness and PEB have an influence on the dose and LCDU to the certain extent. PEB can substantially decrease dose without increasing LCDU too much. From the results of the evaluation, it can be concluded that the CAR resist $\mathrm{C}$ and inorganic resist $\mathrm{B}$ can be considered as a potential candidate for printing high resolution contact holes/pillars. Furthermore, processing parameters, such as film thickness, PEB can be optimized in order to be ready for high-NA EUVL.

\section{ACKNOWLEDGEMENTS}

We are grateful to Markus Kropf for his technical assistance. Part of this work was performed at Swiss Light Source (SLS), Paul Scherrer Institute. 


\section{REFERENCES}

[1] M. v. d. Brink, “Cost-effective shrink with holistic lithography, extended by EUV,” Proc. EUVL Symp., Maastricht, The Netherlands, (2015).

[2] E. Buitrago, M. Meeuwissen, O. Yildirim, R. Custers, R. Hoefnagels, G. Rispens, M. Vockenhuber, I. Mochi, R. Fallica, Z. Tasdemir, and Y. Ekinci, "State-of-the-art EUV materials and processes for the 7nm node and beyond,” Proc. SPIE, 10143, 8 (2017).

[3] C. Fouquet, “EUV Products and Business Opportunity,” ASML SMALL TALK 2018., VELDHOVEN, The Netherlands, (2018).

[4] J. Finders, "EUV lithography: update on scanner and infrastructure progress," EMLC 35th European Mask and Lithography Conference Dresden, Germany, (2019).

[5] T. Wallow, C. Higgins, R. Brainard, K. Petrillo, W. Montgomery, C.-S. Koay, G. Denbeaux, O. Wood, and Y. Wei, Evaluation of EUV resist materials for use at the $32 \mathrm{~nm}$ half-pitch node, Proc. SPIE, 62911F, (2008).

[6] E. Buitrago, R. Fallica, D. Fan, T. S. Kulmala, M. Vockenhuber, and Y. Ekinci, "SnOx high-efficiency EUV interference lithography gratings towards the ultimate resolution in photolithography,” Microelectronic Engineering, 155, 44-49 (2016).

[7] Y. Ekinci, M. Vockenhuber, B. Terhalle, M. Hojeij, L. Wang, and T. R. Younkin, "Evaluation of resist performance with EUV interference lithography for sub-22-nm patterning,” Proc. SPIE, 8322, 11 (2012).

[8] N. Mojarad, D. Fan, J. Gobrecht, and Y. Ekinci, "Broadband interference lithography at extreme ultraviolet and soft x-ray wavelengths,” Optics Letters, 39(8), 2286-2289 (2014).

[9] N. Mojarad, J. Gobrecht, and Y. Ekinci, "Interference lithography at EUV and soft X-ray wavelengths: Principles, methods, and applications,” Microelectronic Engineering, 143, 55-63 (2015).

[10] A. M. Goethals, R. Gronheid, F. Van Roey, H. H. Solak, and Y. Ekinci, "Progress in EUV Resist Performance," Journal of Photopolymer Science and Technology, 19(4), 501-506 (2006).

[11] E. Buitrago, S. Nagahara, O. Yildirim, H. Nakagawa, S. Tagawa, M. Meeuwissen, T. Nagai, T. Naruoka, C. Verspaget, R. Hoefnagels, G. Rispens, G. Shiraishi, Y. Terashita, Y. Minekawa, K. Yoshihara, A. Oshima, M. Vockenhuber, and Y. Ekinci, "Sensitivity enhancement of chemically amplified resists and performance study using extreme ultraviolet interference lithography,” Proc. SPIE, 15, 9 (2016).

[12] Z. Tasdemir, X. Wang, I. Mochi, L. v. Lent-Protasova, M. Meeuwissen, R. Custers, G. Rispens, R. Hoefnagels, and Y. Ekinci, Evaluation of EUV resists for 5nm technology node and beyond, Proc. SPIE, 108090L (2018).

[13] X. Wang, Z. Tasdemir, I. Mochi, M. Vockenhuber, L. v. Lent-Protasova, M. Meeuwissen, R. Custers, G. Rispens, R. Hoefnagels, and Y. Ekinci, Progress in EUV resists towards high-NA EUV lithography, Proc. SPIE, 109570A, (2019).

[14] N. Mojarad, M. Hojeij, L. Wang, J. Gobrecht, and Y. Ekinci, "Single-digit-resolution nanopatterning with extreme ultraviolet light for the $2.5 \mathrm{~nm}$ technology node and beyond," Nanoscale, 7(9), 4031-4037 (2015).

[15] D. Fan, and Y. Ekinci, "Photolithography reaches $6 \mathrm{~nm}$ half-pitch using EUV light,” Proc. SPIE, 9776, 11 (2016).

[16] X. Wang, L.-T. Tseng, D. Kazazis, Z. Tasdemir, M. Vockenhuber, I. Mochi, and Y. Ekinci, "Studying resist performance for contact holes printing using EUV interference lithography,” Journal of Micro/Nanolithography, MEMS, and MOEMS, 18(1), 1-11, 11 (2019).

[17] G. F. Lorusso, T. Sutani, V. Rutigliani, F. v. Roey, A. Moussa, A.-L. Charley, C. Mack, P. Naulleau, V. Constantoudis, M. Ikota, T. Ishimoto, and S. Koshihara, "The need for LWR metrology standardization: the imec roughness protocol”, Proc. SPIE, 105850D, (2018). 